\title{
Noise and context-dependent memory
}

\author{
PAUL A. BELL, SUSAN HESS, ERNIE HILL, SHAWNA LEE KUKAS, \\ RALPH W. RICHARDS, and DAVID SARGENT \\ Colorado State University, Fort Collins, Colorado
}

\begin{abstract}
Thirty-five undergraduate volunteers were presented with four lists of 28 words each. The words were presented via slide projector for 3 sec each, and subjects were given 90 sec after each list to recall as many words as possible. Two of the lists were presented under normal background (55- $\mathrm{dB})$ noise conditions, and the other two with 95- $\mathrm{dB}(\mathrm{A})$ noise present. Recall for one of the 55-dB and one of the $95-\mathrm{dB}$ lists was at $55 \mathrm{~dB}$, and recall for the other two lists was at $95 \mathrm{~dB}$. Results indicated that noise during initial exposure to the word lists impaired subsequent recall, but that noise during recall neither impaired nor enhanced performance.
\end{abstract}

Although intuitively one would expect noise to have deleterious effects on human performance, research has not always been consistent with this expectation. For example, Poulton $(1978,1979)$ suggested that an increase in arousal associated with the initial onset of noise often improves performance, but that subsequent decreases in arousal, plus distraction and interference with auditory cues, leads to impaired performance. Broadbent $(1971,1978)$, alternatively, proposed that noise causes arousal and narrowing of attention, which may lead to improvement of performance on some simple tasks but to decrements on more complex tasks.

Such mixed effects apply to cognitive as well as manual tasks. With multiple tasks, such as visual monitoring combined with a secondary auditory monitoring task, noise typically impairs performance on the secondary task but not on the primary task (e.g., Bell, 1978; Finkleman \& Glass, 1970). Noise may impair shortterm recall of incidental stimuli, but not central stimuli (e.g., Hockey \& Hamilton, 1970; O’Malley \& Poplawsky, 1971). Noise appears to enhance ordered recall but to impair free recall (Daee \& Wilding, 1977; Hockey \& Hamilton, 1970; Jones, 1979; Wilding, Mohindra, \& Breen-Lewis, 1982).

A potential explanation for some mixed effects of noise that has not received attention in the research literature comes from recent work on context-dependent memory, in which recall often has been enhanced when it has occurred under the same environmental or situational conditions under which exposure to the stimuli occurred. Bower (1981), for example, showed that pleasant or unpleasant moods enhance recall of material from past pleasant or unpleasant circumstances, respectively. Godden and Baddeley (1975) similarly reported that scuba divers learnings words on land or un-

Order of authorship is alphabetical. A draft of this manuscript was presented at the Rocky Mountain Psychological Association meeting in Snowbird, Utah, April 1983. Requests for reprints should be sent to Paul A. Bell, Department of Psychology, Colorado State University, Fort Collins, Colorado 80523. der water recalled the stimuli best when the test situation was the same (i.e., on land or under water) as the initial exposure situation. These context effects are typically thought to occur because the context itself comes to serve as an association cue during recall.

Such context effects lead one to ask whether noise might be considered a part of the context and whether stimuli learned under high noise conditions might be recalled better under noisy conditions. Existing literature on noise effects often fails to account for such potential context effects. Research by Heft (1979) is illustrative of this point. It was found that children from noisy homes performed more poorly than children fromquieter homes on an inicidental learning task. The testing situation, however, included relatively quiet circumstances. On another task (matching familiar figures), however, an auditory distraction was present on some trials. Under the distraction condition, children from noisy homes performed better than children from quieter homes. Although these results may be explained in terms of developmental interference and/or adaptation, the context hypothesis should not be ruled out.

An examination of the Method sections of articles reporting research on noise effects on recall reveals that learning and recall typically occur under the same context (i.e., quiet-quiet or noise-noise), although often the presence or absence of noise during recall is not reported. The present experiment was designed to examine potential noise context effects more systematically by manipulating noise level during both the exposure (learning) phase and the recall phase of the memory task. It was predicted that noise during the learning phase would impair performance if recall occurred under quiet conditions, but that noise during recall would enhance performance for words learned under high noise conditions.

\section{METHOD}

\section{Subjects and Design}

The subjects were 35 undergraduate volunteers recruited from a psychology class. The basic design was a $2 \times 2$ within- 
subjects counterbalanced design comprising two noise levels for exposure to word lists $(55 \mathrm{~dB}, 95 \mathrm{~dB})$, and two noise levels during recall for the lists $(55 \mathrm{~dB}, 95 \mathrm{~dB})$.

\section{Procedure}

The subjects, participating individually, entered the $9 \times 12 \mathrm{ft}$ $(2.7 \times 3.7 \mathrm{~m})$ experimental room and signed an informed-consent form that disclosed the high noise level exposure and informed the subjects of their right to terminate the experiment at any time. (No subjects terminated the experiment before all tasks had been completed.) The experimenter then explained that the experiment involved a number of factors in the learning process, and that loud noise would be present from time to time, the purpose of which would be explained at the end of the experiment. It was further explained that words would be presented via slide projector on a screen in front of the subject, with the words to be exposed for $3 \mathrm{sec}$ each. At the end of a list of words, a green slide would appear, at which time the subject was to write down as many words as possible from that list. A time limit of $90 \mathrm{sec}$ was set for each recall session.

Each subject was exposed to the same four word lists, consisting of 28 words each. For each list, words were drawn randomly from the AA range of Thorndike and Lorge (1944), except for the constraints that there be no words with obvious "noise" association and that there be no consecutive words with the same initial letter.

Noise in the room was either $55-\mathrm{dB}(\mathrm{A})$ background noise or white noise amplified through wall speakers to $95 \mathrm{~dB}(\mathrm{~A})$ at the subject's seated position. Two word lists were presented with $55 \mathrm{~dB}$ present, and the other two with $95 \mathrm{~dB}$ present. Recall for one of the 55-dB lists was also under 55-dB conditions, but was under $95 \mathrm{~dB}$ for the other list. Similarly, for the $95 \mathrm{~dB}$ presentation lists, recall for one list was at $55 \mathrm{~dB}$, and recall for the other list was at $95 \mathrm{~dB}$, for a total of four possible conditions. Order of the four conditions was completely counterbalanced across the 35 subjects.

After the last recall period, the subjects were presented with a sheet containing 224 words, of which 112 were from the original four lists and the other 112 were distractors. The experimenter instructed the subjects to mark the words that were from the original lists. This recognition task occurred in $55 \mathrm{~dB}$ for half the subjects and in $95 \mathrm{~dB}$ for the other half. Following this recognition task, the subjects were debriefed and released.

\section{RESULTS}

Analysis of variance on the recall data revealed a significant effect for word position $[F(27,918)=15.74$, $\mathrm{p}<.001]$. Trend analysis indicated a nonsignificant linear trend $[F(1,918)=0.71]$ and the expected quadratic trend $[F(1,918)=75.77, p<.001]$, indicating the typical U-shaped serial position effect.

Means and standard deviations for the four experimental conditions are presented in Table 1 . The analysis of variance treated the two levels (quiet, noise) of the learning phase as one factor and the two levels (quiet, noise) of the recall phase as the second factor. Only

Table 1

Means and Standard Deviations for Quiet and Noise Conditions for Exposure (Learning) Phase and Recall Phase

\begin{tabular}{llllll} 
& \multicolumn{4}{c}{ Learning Phase } \\
\cline { 2 - 3 } \cline { 5 - 6 } Recall & \multicolumn{2}{c}{ Quiet } & & \multicolumn{2}{c}{ Noise } \\
\cline { 2 - 3 } \cline { 5 - 6 } Phase & Mean & SD & & Mean & SD \\
\hline Quiet & 11.03 & 2.97 & & 9.41 & 3.06 \\
Noise & 10.16 & 3.10 & & 9.65 & 2.92 \\
\hline
\end{tabular}

the main effect for the learning phase was significant $[F(1,34)=7.67, p<.01]$, indicating that noise during this phase impaired recall. Analysis of the recognition data revealed no significant effects due to treatment or serial position.

\section{DISCUSSION}

The hypothesis that noise during the learning phase would impair recall under quiet conditions was supported. Moreover, noise during the recall phase did not impair recall, and the absence of an interaction failed to support the hypothesis for context-dependent memory. Thus, the decrements in recall reported by previous researchers appear to depend on noise presented during initial exposure to the stimulus material. Presumably, noise during this phase interferes with attention or rehearsal, or otherwise impairs the encoding of the material. Retrieval of encoded material does not appear to be impaired further by noise.

The failure to find that material encoded during noise exposure is recalled better under noise conditions suggests that, at least for the present procedures, a noise context does not serve as an association cue. The present study, however, was restricted to free recall. Past research has indicated that noise can facilitate ordered recall, and it is possible that noise during ordered recall could enhance recall of material learned during noise conditions.

\section{REFERENCES}

BeLl, P. A. (1978). Effects of heat and noise stress on primary and subsidiary task performance. Human Factors, 20, 749-752.

Bower, G. H. (1981). Mood and memory. American Psychologist, 36, 129-148.

Broadbent, D. E. (1971). Decision and stress. New York: Academic Press.

Broadbent, D. E. (1978). The current state of noise research: Reply to Poulton. Psychological Bulletin, 85, 1052-1067.

Daee, S., \& Wilding, J. M. (1977). Effects of high intensity white noise on short-term memory for position and sequence in a list. British Journal of Psychology, 68, 335-339.

Finkleman, J. M., \& Glass, D. C. (1970). Reappraisal of the relationship between noise and human performance by means of a subsidiary task measure. Journal of Applied Psychology, 54, 211-213.

Godden, D. R., \& Baddeley, A. D. (1975). Context-dependent memory in two natural environments on land and underwater. British Journal of Psychology, 66, 325-332.

HEFT, H. (1979). Background and focal environmental conditions of the home and attention in young children. Journal of Applied Social Psychology, 9, 47-69.

Hockey, G. R. J., \& Hamilton, P. (1970). Arousal and information selection in short-term memory. Nature, 226, 866-867.

Jones, D. (1979). Stress and memory. In M. M. Gruneberg \& P. E. Morris (Eds.), Applied problems in memory. London: Academic Press.

O'Malley, J. J., \& Poplawsky, A. (1971). Noise-induced arousal and breadth of attention. Perceptual and Motor Skills, 33, 887-890.

Poulton, E. C. (1978). A new look at the effects of noise: A rejoinder. Psychological Bulletin, 85, 1068-1079.

Poulton, E. C. (1979). Composite model for human performance in continuous noise. Psychological Review, 86, 361-375.

Thorndike, E. L., \& Lorge, I. (1944). The teacher's wordbook of 30,000 words. New York: Teachers College Press, Columbia University.

Wilding, J., Mohindra, N., \& Breen-Lewis, K. (1982). Noise effects in free recall with different orienting tasks. British Journal of Psychology, 73, 479-486.

(Manuscript received for publication December 14, 1983.) 